\title{
Challenges and Opportunities in Applying a Landscape Ecology Perspective in Ecological Restoration: a Powerful Approach to Shape Neolandscapes
}

\author{
Jean Paul Metzger ${ }^{1 *}$ \& Pedro H. S. Brancalion²
}

\author{
${ }^{1}$ Departamento de Ecologia, Instituto de Biociências, Universidade de São Paulo - USP, São Paulo, SP, Brasil \\ ${ }^{2}$ Departamento de Ciências Florestais, Escola Superior de Agricultura "Luiz de Queiroz" - ESALQ, \\ Universidade de São Paulo - USP, Piracicaba, SP, Brasil
}

\section{Introduction}

Over the last 30 years, ecological restoration has emerged as the central new promise for the reconciliation of societal wellbeing and biodiversity conservation in a human-dominated world (Dobson et al. 1997; Bullock et al. 2011). After an initial phase of scientific consolidation and experience accumulation in the practice of assisting the recovery of degraded, damaged or destroyed ecosystems (sensu SER 2004), ecological restoration is finally considered a global priority for moving towards sustainability (Aronson \& Alexander 2013). In the last decade, many large-scale restoration programs have arisen across the world (see examples in McQueen et al. 2001; Doyle \& Drew 2008; Arriagada et al. 2012; Melo et al. 2013a). Ideally, these pioneer initiatives will be just the first steps of a more ambitious movement towards the restoration of degraded ecosystems at global scales, as targeted by the Bonn Challenge and the Aichi target 15 of the United Nations Convention on Biological Diversity (Menz et al. 2013). In this context, restoration ecologists and practitioners, as well as policy makers, will certainly have to be prepared to adopt new approaches for inducing, planning and implementing restoration programs. Central to this process, will be the fundamental movement from local to large-scale perspective in restoration (Melo et al. 2013b).

The first decades of ecological restoration practice were dominated by small-scale initiatives not integrated at the larger scales. These were sometimes referred as a kind of "environmental gardening" because of their negligible effects in reverting degradation at landscape-scale (Brancalion et al. 2012). As many initiatives were originally primarily

\footnotetext{
*Send correspondence to: Jean Paul Metzger Departamento de Ecologia, Instituto de Biociências, Universidade de São Paulo - USP, Rua do Matão, 321, Travessa 14, CEP 05508-900, São Paulo, SP, Brasil E-mail: jpm@ib.usp.br
}

conducted for regulatory compliance (Ruiz-Jaen \& Aide 2005; Aronson et al. 2011; Rodrigues et al. 2011), many early restoration projects were located in areas pre-defined by legal instruments (e.g. riparian corridors with fixed width) with subsequently limited opportunities for planning restoration efforts using a landscape ecology perspective. Such spatial limitations additionally create barriers for increasing restoration cost-effectiveness and, consequently, for up-scaling both existing and future programs.

However, the tide is turning. Ecological restoration has been recently induced by other forces beyond legal compliance, such as payments for ecosystem services schemes (Palmer \& Filoso 2009), the production of timber and non-timber forest products from native species (Brancalion et al. 2012), and biodiversity offsetting policies (Maron et al. 2012). Even when considering legal instruments, new perspectives have arisen for the spatial allocation of mandatory restoration projects. As a consequence of the increasing spatial scale of restoration programs, rising new demands for restoration projects, and the opportunities created by innovative legal instruments, a better integration between restoration ecology and landscape ecology is needed for mainstreaming successful programs.

\section{Restoration with a Landscape Perspective}

What is a restoration with a landscape perspective? Not all large-scale restorations are in fact, restorations based on landscape principles. Semantic confusion abounds in the use of terms like "landscape restoration", "large-scale restoration", "landscape-scale restoration" and "restoration with a landscape perspective".

Here we define landscape restoration as those initiatives that focus on the restoration of landscape structure, dynamics 
or function, while understanding the landscape as a mosaic of interactive landscape units (Metzger 2001). Restoration targets can vary from the re-establishment of historical landscape configurations or the creation of completely new configurations (i.e. novel landscapes) designed to ensure the delivery of ecosystem goods and services to support human wellbeing.

As restoration generally focuses on improving a landscape focused on human demands, landscape restoration commonly encompasses large areas composed of multiple land-use and land-cover types with different degrees of anthropogenic disturbance. Consequently, restoration across these complex mosaics often targets the restoration of multiple ecological processes, including the reduction of edge effects, re-establishment of biological and hydrological fluxes, reconnection of fragmented habitats, and improvement of landscape scenery. The human interventions targeted by landscape restoration can vary widely, although typically include efforts to increase native vegetation cover and enhance connectivity through the introduction of corridors and living fences or the installation of more permeable matrix habitats (e.g. agroforestry or commercial forestry systems in native forest regions).

However, as the units and boundaries of any landscape depend on the suite of species or process under consideration, landscape mosaics can be defined at multiple spatial scales. Restoration efforts explicitly undertaken to favor one species or group of species should be planned to adequately meet the spatial demands for those species. Consequently, landscape restoration can occur at a wide range of scales, including very local scales, where landscapes cover only some hectares or even some square meters, in cases where focal species or processes use or require very restricted spaces. This decoupling between spatial scales and the incorporation of landscape principles in restoration lies at the heart of why "landscape restoration" and "large-scale restoration" remain nonsynonymous terms.

Conversely, large-scale restoration is not necessarily landscape restoration, in part because it does not always target complex or heterogeneous mosaics. For example, large-scale restoration can be simply focused in the improvement or reestablishment of a single land-cover across a wide region, without consideration of the structural or functional consequences across the whole land mosaic. For example, since 1990 the national reforestation program of China has planted over 4 million ha of forests per year over degraded lands. These plantings predominantly consist of monoculture plantations of non-native trees, and were implemented to simply increase forest cover, with little assessment of the mutual influences between landscape structure and reforestation outcomes (Xu 2011). Such large-scale restoration efforts that think locally, and replicate that thinking widely, by definition do not use a landscape ecology perspective and should not be considered landscape-restoration.
From our point of view, a landscape ecology perspective in restoration encompasses both the actions defined above as "landscape restoration" for the improvement of landscape structure, functions or dynamics, as well local restoration actions that consider the influence of the surrounding landscape structure on restoration outputs. Explicit consideration of how landscape structure affects the ecological processes involved in the restoration process can both (1) optimize local-scale restoration actions and (2) enhance effectiveness in transforming the landscape according to the restoration targets. In the first case, restoration can be locally favored when performed in areas with higher connectivity to potential seed sources or with higher landscape resilience (Tambosi et al. this issue). In these conditions, landscape structure can increase the contribution of natural regeneration processes and thus reduce restoration costs, since passive restoration can be used in place of active restoration (Holl \& Aide 2011). In the second case, an adequate intervention in the landscape composition and configuration can result in faster and more effective outcomes, whether targeting biodiversity conservation (e.g. by improving landscape connectivity, matrix permeability or reducing habitat isolation), reestablishing ecological processes or ecosystem services (e.g. by increasing water provision by protecting or restoring key-areas for aquifer recharge), or by increasing landscape resilience or resistance to new disturbances, such as those associated with climatic changes.

In this context, restoration within a landscape ecology perspective is a powerful tool to modulate landscapes to human wishes and demands, in a process of landscape domestication. Landscape restoration can not only allows a better balance between native and human-dominated areas, but can also define and impose a new landscape configuration that permits to take the maximal advantage of the services that landscapes can provide - whether targeted to agricultural production, biodiversity conservation, provision or regulation services, or a combination of those services. Within this perspective, the restoration of the landscape structure and functioning is not necessarily focused on the returning to the previous, 'pre-disturbance' composition, structure and functions of the landscape. Instead, restoration can be used to create "novel landscapes", or neolandscapes that did not exist in the past and whose composition and configuration are shaped to meet the extant desires and demands of the populations that inhabit or use this space. For example, if the objective is to improve ecosystem services for agricultural production (e.g. pollination, pest control), the desired landscape configuration may require only an intermediate level of native habitat cover and landscape connectivity for the community of species responsible for the focal ecosystem services. Neolandscapes can thus be considered as "cultural landscapes" (Antrop 2005) projected in the future to meet the demand of a changing world.

The paradigm of restoration with a landscape perspective goes beyond restoring pieces of the land or even restoring 
large areas, while ignoring the influence of the landscape structure. We need to move from small-scale "environmental gardening" to large-scale restoration based on landscape ecology principles. This new approach brings new challenges for the restoration science, which needs to understand better the relationships between the landscape structure and all the processes related to ecological restoration, but also offers new opportunities to make restoration more effective. However, there are few studies, conceptual frameworks and methodologies available so far that explored the integration between landscape ecology and ecological restoration (but see Holl et al. 2003).

\section{The Content of the Special Issue}

Our goal in this Special Issue is to provide a collection of papers dedicated to push forward the application of a landscape ecology perspective in ecological restoration projects, as means of assessing the advantages of this integration and providing new tools for those interested in adopting this perspective. This Special Issue explores some of the new challenges and opportunities of this approach in a collection of 11 papers, which is the result of the contribution of 37 authors from six countries. It contains a literature review (Leite et al. this issue) and insightful essays on the interface between landscape ecology and restoration ecology (Oosten this issue; Aronson \& Alexander this issue), provides new case studies (Kauano et al. this issue, Pereira et al. this issue) and methodological approaches to consider landscape principles in restoration action and planning (Tambosi et al. this issue, Echeverria et al. this issue, Gama et al. this issue, Cassiano et al. this issue), and also shows some practical implications for public policies (Garcia et al. this issue, Brancalion et al. this issue).

Leite et al. (this issue) open the Special Issue with a coherent literature revision, including 54 empirical restoration studies published recently in international journals on the integration between landscape ecology and ecological restoration for biodiversity conservation. They demonstrate a remarkable recent increase in research activity in this theme, reinforcing the growing interest of researchers in the integration of these two disciplines. Moreover, they provide evidence that the landscape context indeed plays an important role in the restoration process and present a framework of knowledge gaps and research needed to advance this new field.

The essay from Cora van Oosten shows that while large-scale investments in landscape management and restoration can be an excellent mechanism to achieve different human demands, they also represent complex decision-making processes that may exacerbate conflicts on land-use rights as well as future needs and demands. She argues that landscape governance should be enhanced through an interactive constellation of landscape institutions, institutional bricolage ("the ability of people to creatively combine old and new institutions, and produce hybrid institutions which appropriately serve their purpose"), and learning networks (local and global). This is the principal tool with which inhabitants and other stakeholders can collectively shape their landscapes.

James Aronson and Sasha Alexander call attention to the need for a transdisciplinary approach when planning largescale restoration with a landscape perspective, integrating scientists, professionals and other stakeholders, as well as biological sciences (restoration ecology, landscape ecology and conservation ecology) with human sciences (ecological economics, law and ethics) when dealing with heterogeneous landscapes and human demands. Case studies from South Africa, India, USA and Brazil are provided to illustrate the complexity of this challenge, and to explore some potential solutions of restoring natural capital, resulting in more sustainable landscapes (Wu 2013) or neolandscapes.

The next group of articles includes two research letters that tested the influence of landscape parameters in ecological restoration process in the Atlantic Forest. The first article (Pereira et al. this issue) assessed the influence of the percentage of remaining forest cover and the distance from forest remnants in the regeneration of native woody species in restoration plantings established in a highly fragmented region. Interestingly, they report that the presence of riparian corridors connecting forest remnants and restoration sites doubled the abundance of regenerating plants in restoration, in comparison with non-connected sites. The second paper (Kauano et al. this issue) assessed, in a landscape with much higher forest cover than present in the above-mentioned case study, the effects of local site conditions and landscape parameters in the regeneration of native trees and shrubs in 39 sites under passive or active restoration. Their main finding was that restoration sites located up to $200 \mathrm{~m}$ from old-growth forest remnants, but not from young regenerating forests, have higher tree species richness and abundance.

Further, we have four other research letters that propose new frameworks for restoration prioritization. The first one (Tambosi \& Metzger, this issue) focused in the identification of priority areas for restoration to maximize biodiversity conservation based on the importance of such areas for increasing local landscape connectivity. Their framework was based on multiple local habitat removal and restoration simulations, using a graph theory approach, and was applied to a case study to demonstrate the potential applications of this novel method. The second framework (Gama et al. this issue) is a practical and user-friendly approach to weigh restoration alternatives and consider both legal and landscape-related trade-offs in a spatially-explicit way. The article describes in details the steps of the framework, and reports the results of its application to both the entire Atlantic Plateau of São Paulo and in one specific subwatershed, as means of demonstrating the framework's relevance and flexibility. The third paper (Echeverria et al. this issue) assesses the use of spatial patterns of an edge contrast index for indicating priority restoration areas. Their central goal was to highlight where edge effects could be reduced, 
consequently reducing the conservation risk for edge sensitive and forest-dependent species, as well as for avoiding invasive species colonization of forest remnants. The authors tested their framework in a protected area in central Chile and presented how the outcomes can be used for decision-making in restoration programs. Finally, the last methodological framework (Cassiano et al. this issue) proposes to assess the potential that current forest cover can play in providing water-related ecosystem services. This assessment is based on the balance between local demand for ecosystem services and the potential of forest areas to supply those services, which is evaluated based on three landscape parameters (matrix type, forest age and forest fragment area). The methodology still needs to be tested, but it can be an easy and fast way to prioritize areas for restoration actions aiming to provide water-related ecosystem services.

Two policy forum manuscripts compose the final group of articles, which discuss policies challenges and opportunities of the application of a landscape ecology perspective in ecological restoration projects. The first paper of this section (Garcia et al. this issue) highlighted the challenges brought by the new Brazilian Forest Law for the use of ecological restoration as a tool for increasing landscape connectivity. The authors presented a detailed comparison between the previous and the actual forest law and highlighted many negative, and some (few) positive implications of the law's changes for landscape connectivity. They also provided two case studies that numerically describe the reduction of restoration area required by the new law. The second paper (Brancalion et al. this issue) presents a new concept of nature reserve, called "Restoration Reserves", which combines restoration opportunities with conservation demand at the landscape level in order to create "biodiversity-friendly landscapes" in human-dominated regions. Those reserves should stimulate or facilitate the implementation of largescale restoration within a landscape ecology perspective in private properties. This could be a significant shortcut to allow the restoration of key-landscapes, once most (if not all) land requiring restoration in a landscape perspective is inside private areas, and thus cannot be modified without solving conflicts over land-use rights and resource access through landscape governance (Oosten this issue). Restoration Reserves can be a privileged stage to discuss or attenuate those conflicts, and to facilitate landscape restoration.

\section{Concluding}

We hope that this group of papers can bring new insights for those involved in landscape restoration, and can also stimulate ideas and new hypothesis for the researchers that are building the theoretical base of restoration ecology. Greater consilience between landscape and restoration ecologists carries the promise of a vast improvement in our ability to understand the relationships between landscape structure and function, and in our capacity to plan and create future neolandscapes.

\section{Acknowledgments}

We would like to thank José Alexandre Diniz Filho and Rafael Loyola for accepting and supporting this Special Issue and Elizabeth Nichols for language revision. JPM also thanks the Brazilian Science Council (Conselho Nacional de Desenvolvimento Científico) for a research fellowship.

\section{References}

Antrop, M. 2005. Why landscapes of the past are important for the future. Landscape and Urban Planning, 70:21-34. http:// dx.doi.org/10.1016/j.landurbplan.2003.10.002

Arriagada RA et al., 2012. Do payments for environmental services affect forest cover? a farm-level evaluation from Costa Rica. Land Economics, 88:382-399.

Aronson J et al., 2011. What role should government regulation play in ecological restoration? On-going debate in São Paulo State, Brazil. Restoration Ecology, 19:690-695. http:// dx/doi/10.1111/j.1526-100X.2011.00815.x

Aronson J \& Alexander S, 2013. Ecosystem restoration is now a global priority: time to roll up our sleeves. Restoration Ecology, 21:293-296. http://dx/doi/10.1111/rec.12011

Brancalion PHS et al., 2012. Finding the money for tropical forest restoration. Unasylva, 63:41-50.

Bullock J et al., 2011. Restoration of ecosystem services and biodiversity: Conflicts and opportunities. Trends in Ecology and Evolution, 26:541-549. http://dx.doi.org/10.1016/j. tree.2011.06.011

Dobson AP et al., 1997. Hopes for the future: restoration ecology and conservation biology. Science, 277:515-522. http://dx.doi.org/10.1126/science.277.5325.515

Doyle M \& Drew CA, 2008. Large-scale ecosystem restoration five case studies from the United States. Washington: Island Press.

Holl KD et al., 2003. Landscape restoration: Moving from generalities to methodologies. BioScience, 53:491-502. http://dx.doi.org/10.1641/0006-3568(2003)053[0491:LRMF GT]2.0.CO;2

Holl KD \& Aide TM, 2011. When and where to actively restore ecosystems? Forest Ecology and Management, 261:1558-1563. http://dx.doi.org/10.1016/j.foreco.2010.07.004

Maron M et al., 2012. Faustian bargains? Restoration realities in the context of biodiversity offset policies. Biological Conservation, 155:141-148. http://doi.org/10.1016/j. biocon.2012.06.003

Melo FPL et al., 2013a. Priority setting for scaling-up tropical forest restoration projects: Early lessons from the Atlantic Forest Restoration Pact. Environmental Science \& Policy, 33:395-404. http://doi.org/10.1016/j.envsci.2013.07.013

Melo FP et al., 2013b. On the hope for biodiversity-friendly tropical landscapes. Trends in Ecology \& Evolution, 28:462468. http://doi.org/10.1016/j.tree.2013.01.001

Menz MHM et al., 2013. Hurdles and opportunities for landscape-scale restoration. Science, 339:526-527. http:// dx.doi.org/10.1126/science.1228334 
Metzger, JP. 2001. O que é ecologia de paisagens? Biota Neotropica, 1:1-9. http://dx.doi.org/10.1590/S1676-06032001000100006

McQueen C et al. 2001. The Working for Water Programme. Land-use and Water Resources Research, 1:1-4.

Palmer M \& Filoso S, 2009. Restoration of ecosystem services for environmental markets. Science, 325:575-576. http:// dx.doi.org/10.1126/science.1172976

Rodrigues RR et al., 2011. Large-scale ecological restoration of high diversity tropical forests in SE Brazil. Forest Ecology and Management, 261:1605-1613. http:// doi.org/10.1016/j. foreco.2010.07.005

Ruiz-Jaen MC \& Aide TM, 2005. Restoration success: How is it been measured? Restoration Ecology, 13:569-577. http:// dx.doi.org/10.1111/j.1526-100X.2005.00072.x

$\mathrm{Xu}$ J, 2011. China's new forests aren't as green as they seem. Nature, 477:371. http://dx.doi.org/10.1038/477371a

Wu J., 2013. Landscape sustainability science: Ecosystem services and human well-being in changing landscapes. Landscape Ecology, 28:999-1023.

Received: December 2013

First Decision: December 2013

Accepted: December 2013 